\title{
Experiences of Women in Turkey on Using Complementary and Alternative Medicine Methods Against the Symptoms of Menopause: A Descriptive Study
}

\author{
Hacer Ataman ${ }^{1}(\mathbb{D})$, Yilda Arzu Aba ${ }^{2}$ (D), Melike Dissiz ${ }^{3}$ (D), Sevcan Sevimli ${ }^{4}$ (D) \\ ${ }^{1}$ Istanbul Medeniyet University, Faculty of Health Sciences, Department of Nursing, Turkey. \\ ${ }^{2}$ Bandirma Onyedi Eylul University, Faculty of Health Sciences, Department of Nursing, Turkey. \\ ${ }^{3}$ Health Sciences University, Hamidiye Faculty of Nursing, Department of Obstetrics and Gynecology Nursing, Turkey. \\ ${ }^{4}$ Usak University, School of Health, Turkey.
}

Correspondence Author: Melike Dissiz

E-mail: melekd78@gmail.com

Received: $22.06 .2020 \quad$ Accepted: 14.10 .2020

\begin{abstract}
Objective: The purpose of this study was to determine the efficiency of Complementary and Alternative Medicine (CAM) applications that women have been using against the symptoms of menopause.

Methods: The research was conducted in descriptive design with the women between the ages of 45 and 60 ( $n=629$ ). A “Questionnaire Form" and "Menopause Rating Scale (MRS)" were used in data collection process.

Results: It was determined that women, who were aged 55 and over, were married, had at least 5-year education, and had chronic diseases such as diabetes and hypertension and had treatment for her diseases, obtained higher scores than the total of MRS and sub-dimensions of the scale at a statistically significant level $(p<0.05) ; 52 \%$ of the sample stated that they benefited at least one of CAM methods to cope with menopausal complaints. The most commonly used methods were determined to be praying/worship (33.2\%), massage (19.2\%) and phytotherapy (14.8\%) respectively.

Conclusion: An increase in menopausal complaints were observed in various sub-dimensions of the used scale for those who benefited from praying/worship, massage applications and vitamin/mineral supplements while a decrease in menopausal complaints and an increase in life standards were observed for those who applied hydrotherapy, chiropractic, cup therapy, reflexology and osteopathy methods.

Keywords: Woman, menopause, menopause symptoms, complementary and alternative medicine
\end{abstract}

\section{INTRODUCTION}

According to the definition of World Health Organization (WHO), the menopause is the permanent stop of menstruation as a result of losing the ovary activity (1). A woman, is diagnosed with menopause if she has had amenorrhea (no menses) condition for 12 months $(1,2)$. Symptoms commonly associated with menopause are experienced in the late reproductive years before observable changes in menstrual cycles (2). Certain hormonal, physical and emotional changes are observed in some women starting (premenopause) from nearly four-five years before the menopause and the mentioned changes increase in menopausal period due to the decrease in estrogen hormone. Vasomotor, atrophic and psychological changes are the problems that are experienced in short terms and cardiovascular diseases and osteoporosis are the problems for the long term (1). Almost $40 \%$ of the women in their menopausal period request medical support for the management of menopausal symptoms including hot flushes, night sweating, vaginal dryness and sleep disorders (3).
Hormone therapy is the most effective therapy for menopausal hot flashes. Women with certain medical conditions (such as breast cancer, liver disease, or a history of blood clots) shouldn't use hormone therapy (4). Results of the WHO highlighted multiple concerns regarding the use of estrogen and progestin products in the treatment of menopausal symptoms. Treatment with prescription hormones has been associated with significant adverse effects such as coronary events, deep vein thromboembolisms, stroke, and breast cancer. There has been a resulting increased use and seeking of Complementary and Alternative Medicine (CAM) (5).

Complementary and alternative treatment terms refer to different concepts. If a non-mainstream practice is used together with conventional medicine, it's considered "complementary". If a non-mainstream practice is used in place of conventional medicine, it's considered "alternative". Most complementary health approaches fall into one of two subgroups-natural products or mind and body practices. 
Natural products group includes a variety of products, such as herbs, vitamins and minerals and probiotics. Mind and body practices group includes yoga, chiropractic and osteopathic manipulation, meditation, and massage therapy, acupuncture, relaxation techniques, tai chi, qi gong, healing touch, hypnotherapy and movement therapies (4).

Many natural products have been studied for menopause symptoms. Non-hormonal medicines and methods are also used to treat menopausal symptoms (4). These therapies are increasingly popular among women seeking alternatives to treatment with estrogen for managing menopausal symptoms (3). In 2013, the U.S. Food and Drug Administration (FDA) approved a non-hormonal treatment for hot flashes and a treatment for vaginal symptoms associated with menopause. Phytoestrogens appear to be safe for short-term use. Because phytoestrogen supplements may have effects like those of the hormone estrogen, they may not be safe for women who shouldn't take estrogen. Some of mind and body practices for menopause symptoms might help to relieve symptoms or make them less bothersome (4).

Women, who look for alternative treatments to cope with the menopause symptoms, generally prefer treatment methods that are in compliance with their cultural background. Acupuncture, yoga, relaxation poses, manipulation techniques, meditation, exercise, homeopathy, traditional Chinese teas, natural estrogen sources, diet, vitamins and minerals are among these methods $(5,6)$. Studies in literature show that $42 \%$ of women in USA benefit from CAM methods. Women particularly prefer herbal teas and massage for stress management $(7,8)$. Likewise, use of CAM has increased in Turkey day by day and the rate of use is stated as between $36.0 \%$ and $70.0 \%$ (9).

In the view of the information presented above, this study was conducted with the purpose of determining the species of complementary and alternative medicine methods used against the symptoms of menopause and their effect on severity of symptoms and on women's quality of life.

The specific study questions were:

1. What is the frequency of using CAM methods by menopausal women?

2. Do CAM methods used by women affect menopausal symptoms?

\section{METHODS}

\subsection{Study Design}

The research was conducted descriptive design between January 15 and March 15, 2016 in University of Usak, Faculty of Medicine, Education and Research Hospital, Department of Gynecology. The research population was composed of women between the ages of 45 and 60, who applied to the department of gynecology because of menopausal complaints. The minimum sample size required in the study was determined with the help of power analysis. All calculations in the power analysis to determine the a priori required minimum sample size G-Power 3.1.9.2. was carried out through the program. In the study, the required minimum sample size was calculated to be at least 620 in total with $5 \%$ first type error, 0.10 Cohen standardized effect size, doublesided hypothesis and $90 \%$ working power. The study sample was composed of 629 women who accepted to participate in the study, had no communication deficiency, mental disorders, did not menstruate for at least one year and applied to the department of gynecology between the stated dates with menopausal complaints. Local ethic committee approval was obtained from the mentioned institute for the study (25/01/2016-E.2697).

\subsection{Measures}

A questionnaire form, which was composed of 29 questions and created by the study researchers, was used for data collection and Menopause Rating Scale (MRS) was used for menopausal complaints' evaluation. Women who agreed to participate in the interview and consented in written format to take part in the research were taken to a private room where they would respond to survey questions. The questionnaire and scale were applied by the researchers in face-to-face interviews with women, who accepted to participate in the research and applied to the department for their menopausal complaints as fitting the above stated criteria, by visiting the related department in their convenient days.

The questionnaire form was prepared to investigate the participants' socio-demographic characteristics, obstetric characteristics, health conditions, habits, menopausal histories, and their status of using complementary and alternative medicine applications $(3,5,6,8)$.

MRS was firstly developed in German language to measure the severity of menopause symptoms and their effects on life quality, in 1992 by Schneider, Heinemann et al. International versions, reliability and validity of the scale was made in 2003 by Schneider, Heinemann et al., Turkish form's reliability and validity was made by Gürkan $(2005)(10,11)$. MRS is composed of 11 items for menopausal complaints. 0: none, 1: mild, 2: moderate, 3: severe, 4: very severe are options to choose from in each items. Minimal score that can be taken from the scale is 0 while the maximum is 44 . Likert type scale has three dimensions as somatic (items 1, 2, 3 and 11), psychological (items 4, 5, 6 and 7) and urogenital complaints (items 8, 9 and 10). The increase of total score in the scale shows that the severity of complaints increases and this condition affects life standards negatively. Inner consistency co-efficient of the whole scale was found as 0.84 (11). Cronbach alpha value for this research was determined as 0.81 .

\subsection{Data analysis}

Data analysis for this research was conducted in SPSS (Statistical Package for Social Sciences) 21.0 package program. Number, percentage distribution, $t$ test and oneway Anova tests were used in data analysis. Comparisons 
were considered as significant if respective $p$ values were found below 0.05 as the result of the statistical analyses.

\section{RESULTS}

Average \pm standard deviation (SD) age of the participant women was found as $53.69 \pm 4.40$ (min:45-max:60), majority $(81.7 \%)$ of them were married and more than half $(61.5 \%)$ had primary school and below education levels, $80.3 \%$ of them did not work, $73.8 \%$ of them had nearly equivalent income for their expenses, $81.7 \%$ of them had nuclear family and majority of them lived in the city center.

According to the results, average \pm SD Body Mass Index (BMI) of the women were $27.99 \pm 4.29$ and $73.9 \%$ of them were considered as overweight. They had a chronic disease and, $35,6 \%$ of them had hypertension, $34.3 \%$ of them had diabetes, $22.4 \%$ of them had osteoporosis, $13,8 \%$ of them had psychological issues, $11.6 \%$ of them had musculoskeletal, $11.0 \%$ of them had cardiovascular diseases, and $72.8 \%$ of them regularly used medicine for their chronic diseases respectively. Majority of women, who participated in the study, stated that they did not smoke $(88.1 \%)$ and did not exercise regularly (84.7\%).

In the analysis of socio-demographic factors that affected women's menopausal complaints, those participants who were aged over 55 had statistically significant high scores from the total of scale, those who were married and had at least 5-year education had statistically significant high scores from urogenital sub-dimension of the scale, those who had a chronic disease such as diabetes and hypertension and had treatment for these diseases had statistically significant high scores from total of the scale and its sub-dimensions, those who did not make exercises regularly had statistically significant high scores from only urogenital sub-dimension of the scale $(p<0.05$, Table 1$)$.

Average \pm SD number of pregnancy of women, who participated to the study, was determined as $3.41 \pm 1.62$ (min:0-max:11) and average \pm SD number of children they had was found as $2.81 \pm 1.26$ (min:0-max:10). It was determined that $87.8 \%$ of them entered to menopause period naturally and the rest of them (12.2\% of them) entered the menopause period with surgical ways; and average \pm SD menopausal period was $6.42 \pm 4.90$ (min:1max:27) years. All of them stated that they were supported by their husbands, children, relatives and friends while coping with menopausal complaints however they received the highest support from their husbands (31.2\%). 9.9\% of the participants stated that they had medical treatments during their menopause periods while $52 \%$ of them used one of the CAM methods to cope with their menopausal complaints.

In the analysis of factors that affected menopause symptoms in terms of obstetric-gynecological and menopausal characteristics; women who entered the menopause naturally had significantly higher scores from only urogenital sub-dimension of the scale compared to those who entered to menopause with surgical ways and women who did not receive medical treatment in their menopause periods had significantly high scores from psychological and urogenital sub-dimensions and the total of the scale $(p<0.05)$. Additionally, women who used one of the CAM methods (e.g. phytotherapy, reflexology, massage, and etc.) received higher scores in somatic and urogenital sub-dimensions and the total of the scale $(p<0.05$, Table 2$)$.

Maximal score for the MRS is 44 . According to the analyses, participants received mean \pm SD, $18.90 \pm 8.15$ scores from the total of the scale and $7.79 \pm 3.60$ (min:0-max:16), 7.29 \pm 3.46 (min:0-max:16), 3.82 $\pm 2.67 \quad(\min : 0-\max : 12)$ scores from somatic complaints, psychological complaints and urogenital complaints sub-dimensions, respectively (Table 3).

Women who participated in this research was asked to state which CAM they used to cope with their menopausal complaints. For the most commonly used to least commonly used methods, women stated that $33.2 \%$ of them used praying/worship, $19.2 \%$ of them used massage technics, $14.8 \%$ of them applied phytotherapy, $9.2 \%$ of them took vitamin/mineral supplements, $8.9 \%$ of them made breathe exercises, $8.6 \%$ of them received psychotherapy treatment, $8.4 \%$ of them used hydrotherapy, $7.3 \%$ of them used chiropractic, $5.2 \%$ of them used aromatherapy technics, $4.6 \%$ of them benefited from cup therapy, $4.0 \%$ of them used reflexology and $3.8 \%$ of them used osteopathy method. Majority of women (56.2\%) stated that they used these methods to treat menopausal complaints while $27.1 \%$ of them stated that they used these methods to support the medical treatments related to their complaints.

According to the findings, women, who used praying/ worship as a CAM for their menopausal complaints, had significantly high scores from all sub-dimensions of the scale except from psychological sub-dimension, those who used only massage method had high scores from only urogenital sub-dimension and those who did not use the methodology of taking vitamin/mineral supplements had high scores only from psychological sub-dimension $(p<0.05$, Table 4$)$. On the other hand, women who used hydrotherapy, chiropractic, cup therapy, reflexology and osteopathy methods had significantly lower scores from all sub-dimensions of the scale except from urogenital sub-dimension compared to those who did not use the mentioned methods ( $p<0.05$, Table 4$)$. 
Table 1. Comparison of Score Averages of Menopause Symptoms Rating Scale Sub-Dimensions According to Participants' Characteristics ( $n=629$ )

\begin{tabular}{|c|c|c|c|c|}
\hline \multirow{2}{*}{ Characteristics } & \multicolumn{4}{|c|}{ Menopause Rating Scale } \\
\hline & Somatic Subscale & Psychological Subscale & Urogenital Subscale & MRS Total \\
\hline \multicolumn{5}{|l|}{ Age (years) } \\
\hline$<50(n=177)$ & $7.32 \pm 3,60$ & $6.86 \pm 3,39$ & $3.44 \pm 2,43$ & $17.63 \pm 7.73$ \\
\hline $51-55(n=212)$ & $7.92 \pm 3,69$ & $7.38 \pm 3,60$ & $3.96 \pm 2,73$ & $19.27 \pm 8.40$ \\
\hline$>55(n=240)$ & $8.02 \pm 3,49$ & $7.52 \pm 3,37$ & $3.97 \pm 2,76$ & $19.52 \pm 8.02$ \\
\hline$P^{* *}$ & 0.118 & 0.138 & 0.084 & 0.046 \\
\hline \multicolumn{5}{|l|}{ Marital status } \\
\hline Married $(n=514)$ & $7.78 \pm 3,54$ & $7.31 \pm 3.50$ & $3.96 \pm 2.71$ & $19.06 \pm 8.16$ \\
\hline Single/widow $(n=115)$ & $7.80 \pm 3,86$ & $7.20 \pm 3.31$ & $3.20 \pm 2.37$ & $18.21 \pm 8.10$ \\
\hline$p^{*}$ & 0.956 & 0.774 & 0.005 & 0.315 \\
\hline \multicolumn{5}{|l|}{ Education level (years) } \\
\hline Illiterate $(n=51)$ & $8.07 \pm 3.50$ & $7.19 \pm 3.84$ & $2.82 \pm 2.43$ & $18.09 \pm 7.71$ \\
\hline$<5(n=387)$ & $7.69 \pm 3.75$ & $7.29 \pm 3.62$ & $3.78 \pm 2.67$ & $18.74 \pm 8.60$ \\
\hline$>5(n=191)$ & $7.91 \pm 3.32$ & $7.37 \pm 3.01$ & $4.16 \pm 2.67$ & $19.46 \pm 7.29$ \\
\hline$p^{*}$ & 0.656 & 0.914 & 0.005 & 0.464 \\
\hline \multicolumn{5}{|l|}{ Working status } \\
\hline Yes $(n=124)$ & $7.38 \pm 3.65$ & $7.21 \pm 3.15$ & $3.93 \pm 2.73$ & $18.54 \pm 8.12$ \\
\hline No $(n=505)$ & $7.89 \pm 3.58$ & $7.31 \pm 3.54$ & $3.79 \pm 2.65$ & $19.00 \pm 8.16$ \\
\hline$p^{*}$ & 0.163 & 0.789 & 0.608 & 0.574 \\
\hline \multicolumn{5}{|l|}{ Income status } \\
\hline High income $(n=108)$ & $8.07 \pm 3.14$ & $7.51 \pm 3.50$ & $4.06 \pm 2.73$ & $19.65 \pm 7.58$ \\
\hline Balanced income $(n=521)$ & $7.73 \pm 3.68$ & $7.24 \pm 3.46$ & $3.77 \pm 2.65$ & $18.75 \pm 8.26$ \\
\hline$p^{*}$ & 0.371 & 0.457 & 0.306 & 0.295 \\
\hline \multicolumn{5}{|l|}{ BMI group } \\
\hline Normal $(n=164)$ & $7.58 \pm 3.51$ & $7.31 \pm 3.53$ & $3.98 \pm 2.84$ & $18.88 \pm 8.67$ \\
\hline Over weight $(n=465)$ & $7.86 \pm 3.63$ & $7.28 \pm 3.44$ & $3.76 \pm 2.60$ & $18.91 \pm 7.97$ \\
\hline$p^{*}$ & 0.394 & 0.937 & 0.385 & 0.963 \\
\hline \multicolumn{5}{|l|}{ Chronic health problems } \\
\hline Yes (n: 504) & $8.08 \pm 3.39$ & $7.56 \pm 3.43$ & $4.07 \pm 2.65$ & $19.72 \pm 7.83$ \\
\hline No (n: 125) & $6.60 \pm 4.13$ & $6.19 \pm 3.39$ & $2.82 \pm 2.48$ & $15.62 \pm 8.63$ \\
\hline$P^{*}$ & 0.000 & 0.000 & 0.000 & 0.000 \\
\hline \multicolumn{5}{|l|}{ Regular medicine use } \\
\hline Yes $(n=458)$ & $8.14 \pm 3.41$ & $7.65 \pm 3.43$ & $4.08 \pm 2.62$ & $19.88 \pm 7.79$ \\
\hline No $(n=171)$ & $6.85 \pm 3.91$ & $6.30 \pm 3.38$ & $3.14 \pm 2.67$ & $16.30 \pm 8.53$ \\
\hline$p^{*}$ & 0.000 & 0.000 & 0.000 & 0.000 \\
\hline \multicolumn{5}{|l|}{ Smoking cigarette } \\
\hline Yes $(n=75)$ & $7.85 \pm 3.70$ & $7.69 \pm 3.42$ & $3.60 \pm 2.97$ & $19.14 \pm 8.58$ \\
\hline No $(n=554)$ & $7.78 \pm 3.59$ & $7.23 \pm 3.47$ & $3.85 \pm 2.62$ & $18.87 \pm 8.10$ \\
\hline$p^{*}$ & 0.875 & 0.286 & 0.437 & 0.789 \\
\hline \multicolumn{5}{|l|}{ Regularly doing exercise } \\
\hline Yes $(n=96)$ & $7.63 \pm 4.01$ & $7.63 \pm 3.78$ & $3.12 \pm 2.36$ & $18.09 \pm 8.65$ \\
\hline No $(n=533)$ & $7.81 \pm 3.52$ & $7.23 \pm 3.40$ & $3.95 \pm 2.70$ & $19.00 \pm 8.06$ \\
\hline$p^{*}$ & 0.674 & 0.329 & 0.002 & 0.503 \\
\hline
\end{tabular}

$P^{*}:$ Student's t-test; $P^{* *}$ : One Way-Anova test; BMI: body mass index. 
Table 2. Comparison of Score Averages of Menopause Symptoms Rating Scale Sub-Dimensions According to Participants' ObstetricGynecological and Menopausal Characteristics ( $n=629$ )

\begin{tabular}{|c|c|c|c|c|}
\hline \multirow{2}{*}{ Characteristics } & \multicolumn{4}{|c|}{ Menopause Rating Scale } \\
\hline & $\begin{array}{l}\text { Somatic } \\
\text { Subscale }\end{array}$ & Psychological Subscale & Urogenital Subscale & MRS Total \\
\hline \multicolumn{5}{|l|}{ Number of pregnancies } \\
\hline$\leq 3(n=367)$ & $7.84 \pm 3.63$ & $7.45 \pm 3.38$ & $3.93 \pm 2.77$ & $19.23 \pm 8.28$ \\
\hline$>3(n=262)$ & $7.71 \pm 3.56$ & $7.06 \pm 3.57$ & $3.67 \pm 3.51$ & $18.45 \pm 7.95$ \\
\hline$P^{*}$ & 0.663 & 0.157 & 0.228 & 0.237 \\
\hline \multicolumn{5}{|l|}{ Number of births } \\
\hline$\leq 2(n=291)$ & $7.82 \pm 3.59$ & $7.40 \pm 3.25$ & $4.00 \pm 2.79$ & $19.23 \pm 8.14$ \\
\hline$>2(n=338)$ & $7.76 \pm 3.61$ & $7.19 \pm 3.63$ & $3,67 \pm 2.55$ & $18.63 \pm 8.16$ \\
\hline$P^{*}$ & 0.831 & 0.445 & 0.123 & 0.355 \\
\hline \multicolumn{5}{|l|}{ Gynecological operation status } \\
\hline Yes $(n=147)$ & $8.01 \pm 3.78$ & $7.67 \pm 3.41$ & $3.59 \pm 2.69$ & $19.27 \pm 8.06$ \\
\hline No $(n=482)$ & $7.72 \pm 3.54$ & $7.17 \pm 3.47$ & $3.89 \pm 2.66$ & $18.79 \pm 8.18$ \\
\hline$P^{*}$ & 0.394 & 0.128 & 0.227 & 0.531 \\
\hline \multicolumn{5}{|l|}{ Menopause type } \\
\hline Naturally menopause $(n=552)$ & $7.87 \pm 3.56$ & $7.26 \pm 3.47$ & $3.39 \pm 2.69$ & $19.10 \pm 8.16$ \\
\hline Surgical menopause $(n=77)$ & $7,20 \pm 3.83$ & $7.45 \pm 3.39$ & $2.83 \pm 2.30$ & $17.49 \pm 7.97$ \\
\hline$P^{*}$ & 0.129 & 0.662 & 0.000 & 0.104 \\
\hline \multicolumn{5}{|l|}{ Menopause duration (years) } \\
\hline$\leq 5(n=335)$ & $7.88 \pm 3.65$ & $7.32 \pm 3.52$ & $3.88 \pm 2.59$ & $19.10 \pm 8.35$ \\
\hline $6-10$ years $(n=170)$ & $7.49 \pm 3.64$ & $7.18 \pm 3.47$ & $3.98 \pm 2.63$ & $18.65 \pm 8.11$ \\
\hline$>10(n=124)$ & $7.93 \pm 3.40$ & $7.34 \pm 3.32$ & $3.43 \pm 2.88$ & $18.71 \pm 7.68$ \\
\hline$P^{* *}$ & 0.449 & 0.888 & 0.181 & 0.808 \\
\hline \multicolumn{5}{|c|}{ Medical treatment for menopause } \\
\hline Yes $(n=62)$ & $7.08 \pm 2.91$ & $6.30 \pm 3.35$ & $3.27 \pm 2.20$ & $16.66 \pm 6.61$ \\
\hline No $(n=567)$ & $7.86 \pm 3.66$ & $7.40 \pm 3.46$ & $3.88 \pm 2.71$ & $19.15 \pm 8.27$ \\
\hline$P^{*}$ & 0.056 & 0.018 & 0.046 & 0.007 \\
\hline \multicolumn{5}{|l|}{ Using CAM applications } \\
\hline Yes $(n=327)$ & $8.18 \pm 3.25$ & $7.41 \pm 3.26$ & $4.16 \pm 2.75$ & $19.76 \pm 7.54$ \\
\hline No $(n=302)$ & $7.36 \pm 3.90$ & $7.15 \pm 3.67$ & $3.45 \pm 2.52$ & $17.98 \pm 8.68$ \\
\hline$P^{*}$ & 0.005 & 0.344 & 0.001 & 0.006 \\
\hline
\end{tabular}

$P^{*}:$ Student's t-test; $P^{* *}:$ One Way-Anova test; CAM: complementary and alternative medicine

Table 3. Distribution of participants according to Menopause Rating Scale*

\begin{tabular}{|c|c|c|c|}
\hline Subscale MRS & n & $\%$ & mean \pm SD \\
\hline \multicolumn{4}{|l|}{ Somatic Subscale } \\
\hline Hot flushes/night sweating & 604 & 96.0 & $2.66 \pm 1.12$ \\
\hline Tachycardia & 392 & 62.3 & $1.29 \pm 1.27$ \\
\hline Sleeping problems & 516 & 82.0 & $1.87 \pm 1.19$ \\
\hline Joint and muscular discomfort & 517 & 82.2 & $1.95 \pm 1.26$ \\
\hline \multicolumn{4}{|l|}{ Psychological Subscale } \\
\hline Depressive mood & 540 & 85.9 & $1.80 \pm 1.09$ \\
\hline Irritability & 564 & 89.7 & $2.07 \pm 1.19$ \\
\hline Anxiety & 476 & 75.7 & $1.59 \pm 1.18$ \\
\hline Physical and mental exhaustion & 529 & 84.1 & $1.81 \pm 1.17$ \\
\hline \multicolumn{4}{|l|}{ Urogenital Subscale } \\
\hline Sexual problems & 352 & 56.0 & $1.08 \pm 1.13$ \\
\hline Urinary problems & 462 & 73.4 & $1.45 \pm 1.13$ \\
\hline Vaginal dryness & 415 & 66.0 & $1.28 \pm 1.13$ \\
\hline
\end{tabular}

MRS: Menopause Rating Scale; SD: standard deviation; *participants stated more than 1 symptoms. 
Table 4. Comparison of Score Averages of Menopause Symptoms Rating Scale Sub-Dimensions According to CAM Methods that Participants Used for Their Menopause Symptoms $(n=629)$

\begin{tabular}{|c|c|c|c|c|}
\hline \multirow[b]{2}{*}{ CAM Methods } & \multicolumn{4}{|c|}{ Menopause Rating Scale } \\
\hline & $\begin{array}{l}\text { Somatic } \\
\text { Subscale }\end{array}$ & $\begin{array}{l}\text { Psychological } \\
\text { Subscale }\end{array}$ & $\begin{array}{l}\text { Urogenital } \\
\text { Subscale }\end{array}$ & MRS Total \\
\hline \multicolumn{5}{|l|}{ Praying/worship } \\
\hline Yes $(n=209)$ & $8.40 \pm 3.24$ & $7.63 \pm 3.24$ & $4.49 \pm 2.78$ & $20.52 \pm 7.44$ \\
\hline No $(n=420)$ & $7.48 \pm 3.73$ & $7.12 \pm 3.56$ & $3.49 \pm 3.55$ & $18.10 \pm 8.37$ \\
\hline$P$ & 0.002 & 0.074 & 0.000 & 0.000 \\
\hline \multicolumn{5}{|l|}{ Massage } \\
\hline Yes $(n=120)$ & $8.25 \pm 2.93$ & $6.90 \pm 3.33$ & $4.48 \pm 2.61$ & $19.64 \pm 7.34$ \\
\hline No $(n=509)$ & $7.68 \pm 3.73$ & $7.38 \pm 3.49$ & $3.66 \pm 2.66$ & $18.73 \pm 8.33$ \\
\hline$P$ & 0.074 & 0.177 & 0.003 & 0.238 \\
\hline \multicolumn{5}{|l|}{ Phytotherapy } \\
\hline Yes $(n=93)$ & $7.34 \pm 3.27$ & $7.12 \pm 3.53$ & $3.73 \pm 2.77$ & $18.20 \pm 8.17$ \\
\hline No $(n=546)$ & $7.86 \pm 3.65$ & $7.32 \pm 3.45$ & $3.84 \pm 2.65$ & $19.03 \pm 8.15$ \\
\hline$P$ & 0.194 & 0.623 & 0.714 & 0.367 \\
\hline \multicolumn{5}{|c|}{ Vitamin/mineral supplements } \\
\hline Yes $(n=58)$ & $7.44 \pm 1.99$ & $6.03 \pm 2.62$ & $4.29 \pm 2.09$ & $17.77 \pm 5.46$ \\
\hline No $(n=571)$ & $7.82 \pm 3.72$ & $7.42 \pm 3.51$ & $3.77 \pm 2.72$ & $19.02 \pm 8.37$ \\
\hline$P$ & 0.217 & 0.000 & 0.087 & 0.122 \\
\hline \multicolumn{5}{|c|}{ Breathing exercises } \\
\hline Yes $(n=56)$ & $7.23 \pm 2.91$ & $6.51 \pm 3.30$ & $3.85 \pm 2.58$ & $17.60 \pm 7.20$ \\
\hline No $(n=573)$ & $7.84 \pm 3.66$ & $7.36 \pm 3.47$ & $3.82 \pm 2.68$ & $19.03 \pm 8.23$ \\
\hline$P$ & 0.147 & 0.080 & 0.925 & 0.211 \\
\hline \multicolumn{5}{|l|}{ Psychotherapy } \\
\hline Yes $(n=55)$ & $7.72 \pm 3.11$ & $7.31 \pm 3.42$ & $3.29 \pm 2.45$ & $18.33 \pm 7.29$ \\
\hline No(n=586) & $7.79 \pm 3.64$ & $7.29 \pm 3.47$ & $3.87 \pm 2.68$ & $18.96 \pm 8.23$ \\
\hline$P$ & 0.859 & 0.961 & 0.128 & 0.588 \\
\hline \multicolumn{5}{|l|}{ Hydrotherapy } \\
\hline Yes $(n=53)$ & $6.69 \pm 2.39$ & $6.16 \pm 2.98$ & $3.33 \pm 2.32$ & $16.47 \pm 5.94$ \\
\hline No $(n=576)$ & $7.86 \pm 3.68$ & $7.39 \pm 3.49$ & $3.89 \pm 2.69$ & $19.13 \pm 8.29$ \\
\hline$P$ & 0.001 & 0.014 & 0.121 & 0.004 \\
\hline \multicolumn{5}{|l|}{ Chiropractic } \\
\hline Yes $(n=46)$ & $6.60 \pm 2.09$ & $5.43 \pm 3.20$ & $3.50 \pm 2.29$ & $15.54 \pm 6.13$ \\
\hline No $(n=583)$ & $7.88 \pm 3.68$ & $7.43 \pm 3.44$ & $3.85 \pm 2.69$ & $19.17 \pm 8.23$ \\
\hline$P$ & 0.000 & 0.000 & 0.392 & 0.004 \\
\hline \multicolumn{5}{|l|}{ Aromatherapy } \\
\hline Yes $(n=33)$ & $7.66 \pm 2.89$ & $6.36 \pm 3.56$ & $3.90 \pm 2.42$ & $17.93 \pm 7.04$ \\
\hline No $(n=596)$ & $7.79 \pm 3.63$ & $7.34 \pm 3.45$ & $3.82 \pm 2.68$ & $18.96 \pm 8.21$ \\
\hline$P$ & 0.803 & 0.114 & 0.853 & 0.483 \\
\hline \multicolumn{5}{|l|}{ Cup therapy } \\
\hline Yes $(n=29)$ & $6.75 \pm 2.01$ & $5.58 \pm 3.23$ & $3.41 \pm 2.04$ & $15.75 \pm 5.91$ \\
\hline No $(n=600)$ & $7.84 \pm 3.65$ & $7.37 \pm 3.45$ & $3.87 \pm 2.69$ & $19.06 \pm 8.22$ \\
\hline$P$ & 0.011 & 0.007 & 0.283 & 0.007 \\
\hline \multicolumn{5}{|l|}{ Reflexology } \\
\hline Yes $(n=25)$ & $6.68 \pm 2.24$ & $5.32 \pm 3.32$ & $3.76 \pm 2.27$ & $15.76 \pm 6.08$ \\
\hline No $(n=604)$ & $7.83 \pm 3.64$ & $7.37 \pm 3.45$ & $3.82 \pm 2.68$ & $19.03 \pm 8.20$ \\
\hline$P$ & 0.022 & 0.006 & 0.901 & 0.049 \\
\hline \multicolumn{5}{|l|}{ Osteopathy } \\
\hline Yes $(n=24)$ & $6.79 \pm 2.20$ & $4.79 \pm 3.18$ & $3.95 \pm 2.69$ & $15.54 \pm 6.53$ \\
\hline No $(n=605)$ & $7.83 \pm 3.64$ & $7.39 \pm 3.44$ & $3.81 \pm 2.67$ & $19.04 \pm 8.18$ \\
\hline$P$ & 0.037 & 0.000 & 0.804 & 0.039 \\
\hline
\end{tabular}

$P^{*}:$ Student's t-test; CAM: complementary and alternative medicine; MRS: Menopause Rating Scale 


\section{DISCUSSION}

The study depended on the data regarding species of complementary and alternative medicine methods used against the symptoms of menopause and their effect on severity of symptoms and on women's quality of life.

In our study, the number of women, who naturally entered the menopause period and used CAM, was higher. Peng et al. (12), determined that use of CAM was in low rates among women who had hysterectomy or oophorectomy. In the related study, women, who had more severe somatic and urogenital symptoms, were those who entered to menopause naturally. Use of CAM methods can be analyzed according to the ways that they enter the menopause period.

Women in our study preferred CAM more than medical treatments to cope with menopause symptoms. Use of CAM methods to reduce the severity of menopause symptoms was common among these women (13-15). In the study that CAM methods were found to be commonly used among women, these methods were considered as more secure than Hormone Replacement Therapy (14). The factors of preferring CAM methods are attributed to the fact that they are easily reachable, their applications are economic and there are the effects of socio-cultural characteristics. In this sense, the reasons for using CAM methods can be researched.

In this study, 96\% of women stated that they had hot flush/ night sweating symptoms. Hot flush, which is caused by vasomotor inconsistency, is the most common symptom of climacterics (16-18). Almost $75 \%$ of perimenopausal or postmenopausal women in west societies have hot flushes (16). It was found in literature that physical exercise and consumption of soya products were effective on reducing vasomotor related complaints (19). Use of non-prescribed creams involving progesterone in USA and Canada has been steadily increased. This cream is made of soya beans and wild sweat potato, and is equivalent to endogen progesterone. This preparation is promoted in many radio and TV programs and in websites to be used in various doses, forms and by adding different elements. Many producers recommend creams with progesterone as a supplement to daily diet (20). In the study of Gartoulla et al. (2015), the prevalence of use of CAMs for vasomotor symptoms was $13.22 \%$ (21).

Hot flushes can cause insomnia, sleep disorders, thus they many cause cognitive and effective disorders (22). Decrease in estrogen levels in menopause can cause sleep disorders by decreasing the serotonin metabolism that has an important role on regular sleep routine (23). In a study of Olivera et al. (24), 32 passive and therapeutic treatment massage sessions were applied as twice per week to the patients, who had sleep disorders and did not have a medical treatment. The patients were evaluated following the $6^{\text {th }}$ and $32^{\text {nd }}$ sessions and a significant difference was observed between the massage treatments and the decrease in sleep symptoms in the group to which the therapeutic massage was applied (24). In our study, the frequency of sleep disorder incidents was found to be $82 \%$. However, a significant relationship between massage treatment and somatic symptoms could not be found. In the analysis of research findings, chronic diseases were observed to be a significant factor which caused sleep disorders. Additionally, details of massage treatments may be questioned, therefore, further studies must be conducted in this area. It is important that nurses inform women about treatment alternatives to cope with sleep disorders.

Significant relationship between physical activity, the use of phytotherapy and menopause symptoms could not be found in our study. This result could be attributed to the limited number of participants, who made regular physical activities $(n=96)$ and used phytotherapy method $(n=93)$. Exercise is an important factor to cope with osteoporosis, to prevent cardiovascular health, and to prevent and improve social and psychological well-being $(23,25)$. Moreover, in the analysis of the findings of our study, it was observed that $72.8 \%$ of participants took medicine regularly. In this condition, an exercise program that is unique and convenient to individuals' conditions should be recommended in supervision of an expert. Low level of phytotherapy usage could be attributed to the worry that the use of medicine and herbal products together might cause toxic effects on the participants who had medical treatment due to chronic diseases.

Praying/worship was the most commonly preferred method to cope with menopause symptoms in this study. Despite this conclusion, any positive effects of praying/worship on a menopause symptom severity could not be found (i.e. praying/worship did not decrease severity of any menopause symptoms). In a study, herbal treatments, diet, exercise and massage were found to be the most commonly used CAM methods (26). In a study of Buhling et al. (27), change in life style was found to be the most effective CAM while phytoestrogen treatment was found as the weakest method. According to the study of Peng et al. (28), yoga/meditation was commonly used among women who entered the menopause period naturally and had hysterectomy, on the other hand the method of taking vitamins and herbal medicine was the most commonly used one among women whose ages ranged from 59 to 64 . In another study, dietary treatments and taking herbal medicine were found as the most commonly used methods, which were followed by applying physical methods (29). Accordingly, various methods are preferred to cope with menopausal symptoms. These methods vary depending on the differences such as cultural characteristics and personal/ social factors. In a study of social and cultural factors' effects on the use of CAM, van der Sluijs et al. (30) stated that differences in the use of the CAM methods were caused by the reachability of CAM methods, education level of women and their occupational status. In another related study, it was presented that German gynecologists generally had positive experiences with CAM in their patient's treatments (31). Another reason of benefiting from CAM methods was attributed to the fact that their side effects were fewer and in lower severity than medical treatments.

It was determined in our study that hydrotherapy, chiropractic, cup treatment, reflexology and osteopathy 
among the methods that were preferred to cope with menopause symptoms were effective on decreasing the severity of especially somatic and psychological complaints and taking vitamin and mineral supplements was effective on decreasing the severity of psychological complaints.

\section{Limitations}

This study cannot be generalized to all menopausal women, since this study was conducted only with women who applied to Usak Faculty of Medicine Education and Research Hospital Department of Gynecology.

\section{CONCLUSION}

In direction of the conducted studies, it could be said that patients use CAM methods to cope with especially somatic and psychological symptoms and this is effective on their life qualities. Today, many CAM methods have become a part of modern medicine and has been increasingly used among women who have to cope with menopause symptoms. Therefore, health professionals have been facing the women who use CAM methods or women who would like to learn about these methods. Health professionals should have evidence based and sufficient level of knowledge and experiences about menopause symptoms and CAM methods. It is important that a nurse, as being a health professional, knows CAM methods that can be used in the management of menopause symptoms and inform doctors about this subject, in terms of increasing the effectiveness of the service that is given to patients. Nurses have many opportunities.

Special training programs about menopause period can be organized for women and can be promoted in press, internet and media, so that effective use of methods can be maintained by creating awareness about women's getting professional help from expert health professionals instead of their acquaintances.

\section{REFERENCES}

[1] World Health Organization (WHO). (1996). Research on the menopause in the 1990s. Report of a WHO scientific group. Geneva.

[2] Freeman EW, Grisso JA, Berlin J, Sammel M, Garcia-Espana B, Hollander L. Symptom reports from a cohort of African American and white women in the late reproductive years. Menopause 2001; 8(1):33-42.

[3] Nedrow A, Miller J, Walker M, Nygren P, Huffman L.H., Nelson HD. Complementary and alternative therapies for the management of menopause-related symptoms. Arch Intern Med. 2006; 166:1453-1465.

[4] National Center for Complementary and Integrative Health (NIH), (2018). https://nccih.nih.gov/health. (Accesse date October 10, 2019).

[5] Moore TR, Franks RB, Fox C. Review of efficacy of complementary and alternative medicine treatments for menopausal symptoms. J Midwifery Womens Health. 2017; 62(3):286-297.
[6] Tortumluoğlu G, Pasinlioğlu T. Assign the use age of altenative treatments by women who have climacteric complaints. Journal of Atatürk University Nursing School 2003;6(3): 64-76.

[7] Eisenberg DM, DavisRB, Ettner SL, Appel S, Wilkey S, Van Rompay M,Kessler R C. Trends in alternative medicine use in the United States, 1990-1997: Results of a follow-up national survey. JAMA 1998; 280:1569-1575.

[8] Newton KM, Buist DS, Keenan NL, Anderson LA, LaCroix AZ. Use of alternative therapies formenopause symptoms: Results of a population-based survey. Obstet Gynecol. 2002; 100(1):18-25.

[9] Yavuz M, Illçe AÖ, Kaymakçı Ş, Bildik G, Dıramalı A. Examinatıon of the complementary and alternative treatment use with breast cancer patients. Turkiye Klinikleri J Med Sci. 2007; 27:680-686.

[10] Heinemann LAJ, Potthoff P, Schneider HPG. International versions of the Menopause Rating Scale (MRS). Health Qual Life Outcomes 2003;1:28.

[11] Gürkan ÖC. Reliability and validity of the Turkish version of the Menopausal Symptoms Rating Scale. Nurse Forum 2005; 3035.

[12] Peng W, Adams J, Hickman L, Sibbritt DW. Longitudinal analysis of associations between women's consultations with complementary and alternative medicine practitioners/use of self-prescribed complementary and alternative medicine and menopause-related symptoms, 2007-2010. Menopause 2016; 23(1):74-80.

[13] Bair YA, Gold EB, Zhang G, Rasor N, Utts J, Upchurch DM, Chyu L, Greendale GA, Sternfeld B, Adler SR. Use of complementary and alternative medicine during the menopause transition: Longitudinal results from the study of women's health across the nation. Menopause 2008;15(1):32-43.

[14] Kang HJ, Ansbacher R, Hammoud MM. Use of alternative and complementary medicine in menopause. Int J Gynecol Obstet. 2002; 79(3):195-207.

[15] van der Sluijs CP, Bensoussan A, Liyanage L, Shah S. Women's health during mid-life survey: the use of complementary and alternative medicine by symptomatic women transitioning through menopause in Sydney. Menopause 2007;14(3):397403.

[16] Freedman RR. Hot flashes: Behavioral treatments, mechanisms, and relation to sleep. The Am J Med. 2005; 118(12):1410.

[17] Girardi A, Piccinni C, Raschi E, Koci A, Vitamia B, Poluzzi E, De Ponti F. Use of phytoestrogens and effects perceived by postmenopausal women: Result of a questionnaire-based survey. BCM Complement Alter Med. 2014;14(262).

[18] Vicdan K. Menopause and hormone replacement treatment. Vicdan K, Işık AZ, editors. The Johns Hopkins Manual of Gynecology and Obstetrics. 2000. p. 326.

[19] Morelli V, Naquin C. Alternative therapies for traditional disease states: Menopause. Am Fam Physician 2002; 66(1):2934.

[20] Elavsky S, McAuley E. Physical activity, symptoms, esteem, and life satisfaction during menopause. Maturitas 2005; 52:374385.

[21] Gartoulla P, Davis SR, Worsley R, Bell RJ. Use of complementary and alternative medicines for menopausal symptoms in Australian women aged 40-65 years. Med J. 2015; 203(3): 146.

[22] Yücel A. Menopause and hormone treatment. Günalp S, Tuncer S, editors. Gynecology and obstetrics diagnosis and treatment. Pelikan Publishers;2004. p.588. 
[23] Şahin NH. Klimakterium period and menopause. Beji NK, editor. Women's health and diseases for nurses and midwife. Istanbul: Nobel Medical Publishers; 2nd ed., 2017. p.163-170.

[24] Oliveria DS, Hachul H, Goto V, Tufik S, Bittencourt RA. Effect of therapeutic massage on insomnia and climacteric symptoms in postmenopausal women. Climacteric 2012; 15(1): 21-29.

[25] Özkan S. Climacterium and menopause. Şirin A, Kavlak O, editors. Women's health. Istanbul: Nobel Medical Publishers; 2nd ed., 2016. p.160.

[26] Koç Z, Saglam Z, Topatan S. Determination of the use of complementary and alternative medicine by women in the climacteric period in the Turkish city of Samsun. Contemp Nurse 2013; 45(2):197-209.

[27] Buhling KJ, Daniels BV, Studnitz FS, Eulenburg C, Mueck AO. The use of complementary and alternative medicine by women transitioning through menopause in Germany: Results of a survey of women aged 45-60 years. Complement Ther Med. 2014; 22(1): 94-98.
[28] Peng W, Sibbritt DW, Hickman L, Adams J. Association between use of self-prescribed complementary and alternative medicine and menopause-related symptoms: A cross-sectional study. Complement Ther Med. 2015; 23(5): 666-673.

[29] Gerber LM, Mamtani R, Chiu YL, Bener A, Murphy M, Cheema $\mathrm{S}$, VerjeeM. Use of complementary and alternative medicine among midlife Arab women living in Qatar. East Mediterr Health J. 2014; 20(9):554-560.

[30] van der Sluijs C, Lombardo FL, Lesi G, Bensoussan A, Cardini F. Social and cultural factors affecting Complementary and Alternative Medicine (CAM) use during menopause in Sydney and Bologna. Evid Based Complement Alternat Med. 2013; 17(3):1-6.

[31] von Studnitz FS, Eulenburg C, Mueck AO, Buhling KJ. The value of complementary and alternative medicine in the treatment of climacteric symptoms: Results of a survey among German gynecologists. Complement Ther Med. 2013; 21(5):492-495. 